\title{
Solar energy and photovoltaic: technical background and basics knowledge teaching using an innovative Solar Production Simulator
}

\author{
S. Jacques ${ }^{1}$, Z. Ren ${ }^{1}$, A. Caldeira ${ }^{1}$, A. Schellmanns ${ }^{1}$, N. Batut ${ }^{1}$, T. Jacques ${ }^{2}$, and E. Pluvinet ${ }^{2}$ \\ ${ }^{1}$ University of Tours, GREMAN UMR-CNRS 7347, Polytech Tours, Electronics and Energy Department \\ 7 avenue Marcel Dassault, 37200 Tours (France) \\ ${ }^{2}$ Freevolt SARL, 12 avenue des Prés, 78180 Montigny-le-Bretonneux (France) \\ Phone number: +33 2473613 25, e-mail: sebastien.jacques@univ-tours.fr
}

\begin{abstract}
This paper deals with a new pedagogical approach that intends to facilitate the acquisition of basic knowledge regarding solar energy and photovoltaic applications. This experimental and interactive teaching method enables students and designers of photovoltaic systems to manipulate a Solar Production Simulator (SPS). This simulation tool reproduces, on a small scale, the sun's path at any time of day. It estimates the energy production of a solar sensor in various inclinations and orientations using an easy-to-use operator interface. The SPS offers students an opportunity to learn in another way solar energy background. Several examples of practical work are detailed to give an overview of the learning exercises that could be done by students to acquire basics in solar energy and photovoltaic applications. For example, many applications could be studied such as implementation of solar position calculations, electrical characterization of solar cells with various technologies or tracking system programming.
\end{abstract}

\section{Key words}

Course construction, Solar energy, Photovoltaic, Solar Production Simulator, Attractiveness of education.

\section{Introduction and purpose}

The renewable energy deployment issue gets a headline regularly since it must be seen in the context of achieving climate change and greenhouse gas reduction targets [1], [2], [3]. According to the national energy agency networks, world energy consumption may grow by more than one and a half times each year if any measure is set up to reduce this energy consumption [4]. Examples of action are the 20-20-20 goals tracked by the European Union [5]. This plan consists in reaching a $20 \%$ reduction of $\mathrm{CO}_{2}$ emissions, a $20 \%$ share of energy from lowcarbon energy sources and $20 \%$ reduction in the use of primary energy by improving energy efficiency by 2020 [6]. The need to protect the environment, particularly by limiting the use of fossil fuels, is also reflected in habitat in which solar energy is heavily used especially for countries with a supportive legislative and fiscal framework [7], [8].

Electronic engineering and energy school curricula have to be necessarily in line with the ongoing energy and environmental objectives [9]. New teaching methods have to be set up to get a better understanding of renewable energy sources for sustainable development and to promote awareness to long-term behavioral change.

A new Solar Production Simulator (SPS) has recently been invented by a French society (Freevolt SARL) located in the greater Paris area and developed at the University of Tours (French engineering school) to provide students with first-hand experience and knowledge of solar energy and particularly, photovoltaic applications. This simulator has been awarded with gold medals at the 2012 International Invention Exhibition Concours Lépine in Paris.

The SPS is a pedagogical tool that reproduces, on a small scale, the sun's path at any time of day. It estimates the energy production of a solar sensor in various inclinations and orientations. Existing solar simulator solutions are not well-appropriated to the characterization of solar sensors in real operating conditions, particularly in case of partial shading or solar radiation nonperpendicular to the sensor surface. In the meantime, the impact of partial shading on the energy production has been widely discussed [10]. The SPS takes into consideration these issues.

In this paper, many detailed information about the functioning of the SPS are given. Several examples of practical work to perform within the same equipment are described. These learning exercises are intended for students in their final year of high school, technicians or engineering students. In particular, the use of the SPS may help students to simulate the solar energy unit production on a particular geographic location. These students could, among other things, measure the electrical performances of a solar cell (open-circuit voltage, short-circuit current etc.), compare solar sensor technologies and analyze the effects of shading from nearby objects on the solar energy unit production.

The students completed a satisfaction survey at the end of the practical works. A summary of the results is given at the end of this article. 
The SPS promises to bring about new opportunities for solar energy and photovoltaic applications for teaching, making the courses more attractive for students.

\section{Course learning objectives}

The third year students of the Electronic engineering and Energy department at the University of Tours in France, in the context of their training program, receive a course entitled "Management of solar energy and photovoltaic applications". This course, which is part of the area of electrical energy systems, covers fundamental knowledge of solar energy and reviews the design, installation, operation and evaluation of solar photovoltaic systems intended for use in residential applications.

The course consists of 12 hours of lectures and 12 hours of practical works using the SPS to illustrate the technical concepts explained during the lessons. Topics that are covered include the solar energy fundamentals, photovoltaic market situation, solar cells, photovoltaic modules and areas, photovoltaic plant sizing and analysis of performances. At the end of this training program, the students are expected to identify the main drivers behind solar photovoltaic and make a valued judgment on the suitability of a photovoltaic system for a given situation.

Students are assessed and informed of their progress on an on-going basis throughout the program. They may also be involved in the continuous improvement process of the operation of the SPS. The method of teaching is referred to as outcome-based education [11]. In this way, this approach enables students to increase and improve their skills to respond quickly and flexibly to changing renewable market requirements.

\section{Operating principle of the SPS}

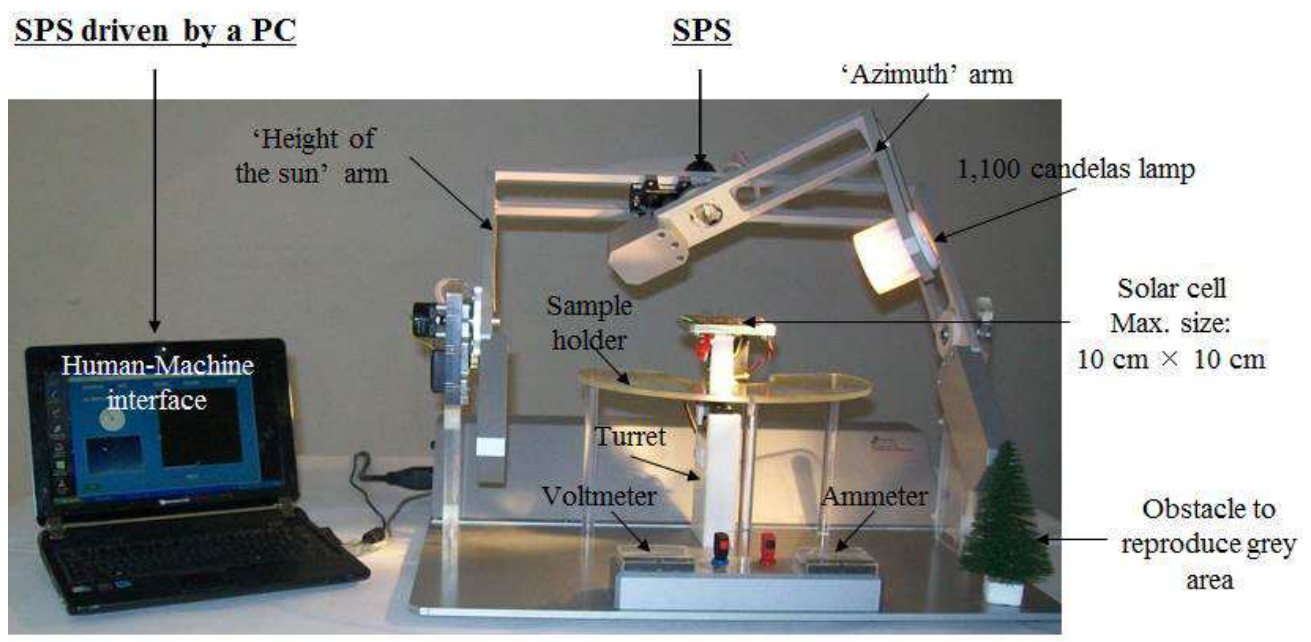

Fig. 1. Key elements of the SPS.

\section{B. Human-machine interface features}

The SPS is entirely driven by a PC using an USB port. It is possible to implement a fully automated system with the help of the LabVIEW programming environment

\section{A. Hardware part characteristics}

The simulator is $55 \mathrm{~cm}$ long and $46 \mathrm{~cm}$ wide. Its mechanical structure was completely designed, manufactured and assembled by Freevolt Concept.

As can be seen in Fig. 1, the sun's path is materialized using a $50 \mathrm{~W}$ halogen lamp which is connected to a $12 \mathrm{~V}$ DC low voltage input. Its light intensity, specified by the manufacturer, is equal to 1,100 candelas with a $60^{\circ}$ angle of half-intensity cone. This lamp has been calibrated previously. Specifically, the light flux must cover the whole surface of the $10 \mathrm{~cm} \times 10 \mathrm{~cm}$ solar cell. As a consequence, the "lamp - solar cell" pairing has been done by testing more than 40 lamps. Using this method, the spectral data are not necessary to size the lamp since it is dedicated to the solar cell dimensions. However, it could be interesting to use Xenon lamps since their spectral characteristics are close to the Sun ones (standard solar spectrum like AMG1.5).

Two servomotors allow controlling the azimuth amplitude and height level of the sun. The maximum azimuth amplitude and elevation of the sun are equal to $42.7 \mathrm{~cm}$ and $45.4 \mathrm{~cm}$ respectively. Thus, the values of the azimuth angle are in the range of $-90^{\circ}$ to $90^{\circ}$. Regarding the elevation of the sun, its maximum value is equal to $90^{\circ}$. The circuit controlling the movement of the SPS uses a microcontroller board (Arduino Duemilanove) based on the ATMEGA 328. The kit is composed of a turret on which a $10 \mathrm{~cm}$ long and $10 \mathrm{~cm}$ wide solar cell $(0.15 \mathrm{Wp})$ could be magnetized. Amorphous, monocrystalline and polycrystalline solar cell technologies can be used. A sample holder that incorporates a graph of the sun's path in any geographic location helps to define solar masks. It requires putting obstacles on the sample holder such as trees that could reproduce shady areas on the solar system. 
As can be seen in Fig. 2, the simulation interface is composed of five main parameters that have to be defined.

Firstly, it is necessary to select the city in which the simulation has to be performed. An array of location in Europe (GPS coordinates) is included in the programming environment. Then, it is possible to choose the technology of the solar cell from amorphous, monocrystalline and polycrystalline silicon. The software includes weather databases. Thus, the solar energy production simulation can be estimated by weighting the weather conditions (full sunshine, cloudy, rainy conditions). The light intensity of the lamp is adjusted in relation to the weather conditions. The solar sensor surface of the building (such as a house) that we wish to predict its energy production is also an input. The system theoretically calculates its peak output solar power. Finally, the azimuth angle and height level of the sun can be set up to take into consideration the orientation and inclination of the building.

The software interface allows the SPS to have three main operation modes: "day" mode, "month" mode, "year" mode.

Each mode allows displaying the solar energy production directly in the simulation interface. A report containing any relevant information (input and output data) concerning the simulation could be created automatically. The output data such as the voltage and current of the solar cell could be exported to a spreadsheet to be analyzed.

It is important to notice that it is possible to minimize the effect of the ambient light by performing a calibration cycle to better calculate the solar energy production. For this, the simulator measures the ambient light when the lamp is turned-off, then takes the value into account in the simulation results.

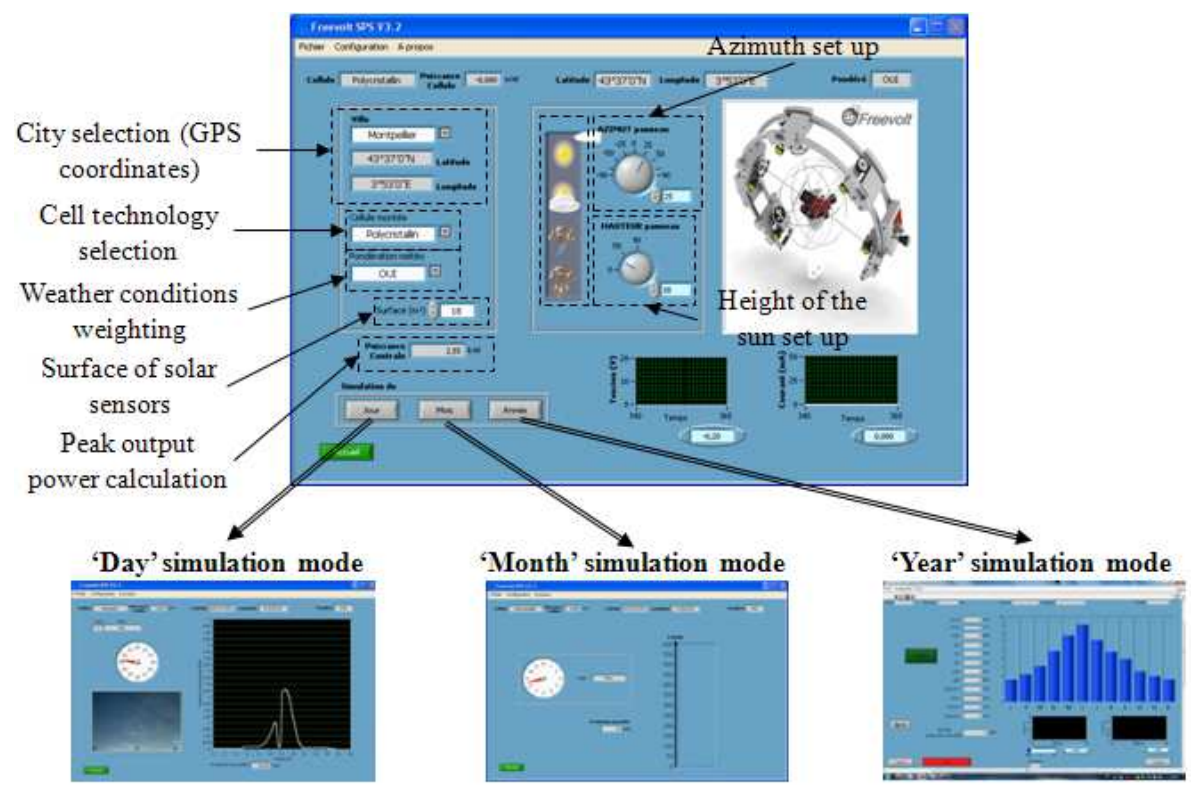

Fig. 2. Human-machine interface of the SPS.

\section{Description of practical works}

\section{A. Purpose}

In this section of the paper, three examples of practical work are detailed. These exercises are held as part of the course entitled "Management of solar energy and photovoltaic applications" described previously. The practical works were conducted by third year engineering students.

The first two exercises help to learn how to use the SPS to get a better understanding of its operating modes. The last practical work is related to programming a microcontroller to develop a solar tracking system. The students completed a satisfaction survey at the end of these practical works. A summary of the results is given at the end of this section.

\section{B. Examples of exercise related to the operating of the SPS}

The first practical work gives the method to measure the open-circuit voltage and the short-circuit current of the solar cell by determining its I-V characteristics. This curve can be plotted by varying the load resistance (for instance, using a decade resistance box). This graph is useful to extract the maximum power point of the photovoltaic cell (see Fig. 3). 


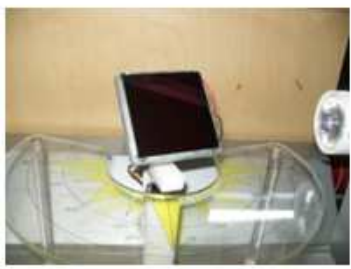

$0.15 \mathrm{Wp}$ amorphous solar cell

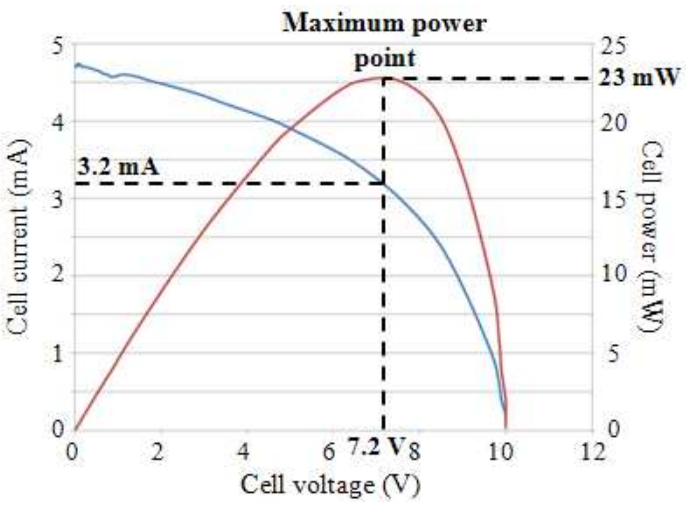

Fig. 3. First practical work related to the operating of the SPS: example of $0.15 \mathrm{Wp}$ amorphous solar cell characterization results.

The second exercise consists in getting a better understanding of the impact of the photovoltaic sensor orientation and inclination on the energy production of the solar plant. This kind of simulation has to be performed in one place. The orientation and tilt angle of the solar sensor are the only parameters to be adjusted.

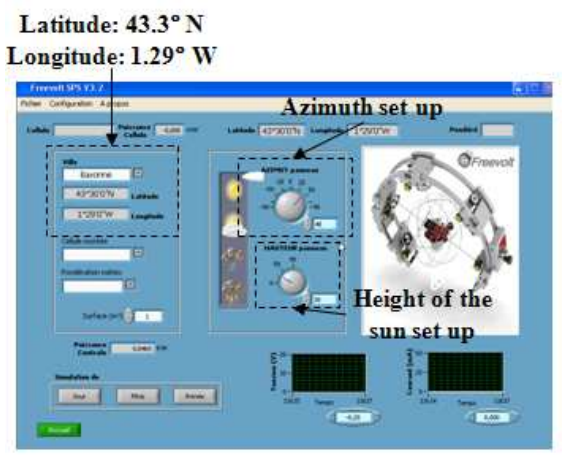

The solar energy production can be calculated for each orientation and inclination value. As can be seen in Fig. 4, the data could be analyzed using a spreadsheet to extract the optimal values of the orientation and tilt angle to maximize the energy production.

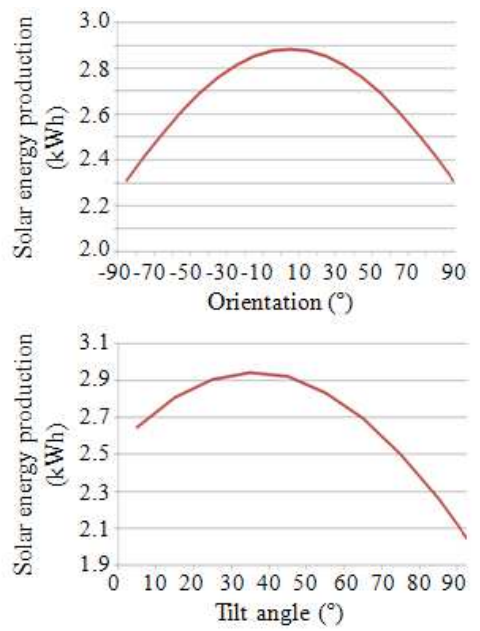

Fig. 4. Second practical work linked to the operating of the SPS: example of impact of orientation and tilt angle on the solar energy production.

\section{Example of exercise related to programming}

This section of this paper is dedicated to the presentation of another application of the SPS related to programming. The SPS could be equipped with an autonomous turret that includes an ATMEGA 328 microcontroller. The servomotors dedicated to the control of the cell displacements (inclination and orientation) could directly be programmable by the students. The rotary motion of these motors is transferred to the actuator stem via a gear unit. Clockwise and anticlockwise rotations are possible. This programming application covers a wide range of tracking systems: mono-axial mode with azimuth moving, mono-axial mode with height level of the sun moving, biaxial mode.

\section{Students' feedback}

The thirty third year engineering students of the Electronic engineering and Energy department had the opportunity to use the SPS during the exercises so as to motivate to apply themselves practically.

Each student filed a questionnaire at the end of the practical. The aim of this questionnaire is to give an overall satisfaction score of the simulator, and its utility in the learning process. In particular, four questions were highlighted and scored on a scale of ' 1 ' to ' 4 '. The ' 1 ' and ' 4 ' marks are the lowest and highest evaluations of each question respectively [12]. Table 1 summarizes the results. A total satisfaction score of $83.5 \%$ was obtained for the SPS. The students' feedback is helpful to improve the functioning of the simulator. 
Table 1. Satisfaction survey summary.

\begin{tabular}{lcccccc}
\hline \multicolumn{1}{c}{ Question } & Poor $=1$ & Good = & Very good =3 & Excellent =4 & $\begin{array}{c}\text { Average } \\
\text { score }\end{array}$ & $\begin{array}{c}\text { Satisfaction } \\
\text { score }\end{array}$ \\
\hline $\begin{array}{l}\text { 1. Did you benefit from } \\
\text { this teaching approach to } \\
\text { learn basics of } \\
\text { photovoltaic? }\end{array}$ & $2.1 \%$ & $12.3 \%$ & $41.2 \%$ & $44.4 \%$ & 3.28 & $82.0 \%$ \\
$\begin{array}{l}\text { 2. Did you improve your } \\
\text { skills in solar energy } \\
\text { applications? }\end{array}$ & $2.5 \%$ & $11.2 \%$ & $39.7 \%$ & $46.6 \%$ & 3.30 & $82.5 \%$ \\
$\begin{array}{l}\text { 3. Score the easy way to } \\
\text { use the SPS. }\end{array}$ & $1.3 \%$ & $4.9 \%$ & $51.2 \%$ & $42.6 \%$ & 3.35 & $83.8 \%$ \\
$\begin{array}{l}\text { 4. Score the specific use } \\
\text { of the SPS. }\end{array}$ & $1.2 \%$ & $7.9 \%$ & $37.3 \%$ & $53.6 \%$ & 3.43 & $85.8 \%$ \\
Total satisfaction score & & & & & $\mathbf{8 3 . 5 \%}$ \\
\hline
\end{tabular}

\section{Conclusion}

The Solar Production Simulator (SPS) described in this paper is an innovative educational tool to give technical background and basics knowledge of solar energy and photovoltaic applications in a playful way.

The operating modes of the SPS are widely described. This tool has many applications. Several examples of practical work are described (this list of exercises is not meant to be exhaustive): solar cell electrical characterization, solar energy production prediction of a power plant with various environmental constraints (for instance, partial shading), tracking system programming or introduction of astronomy basics (for example, solar position calculations). Most importantly, the students participate in an interactive learning process using this approach.

While the interest of this simulator is before all pedagogical, it could allow estimating the energy efficiency of a photovoltaic sensor when it is put into a situation in habitat applications. Thus, it could look forward to helping designers develop the best layout for a solar plant. This simulator could also act as a demonstrator dedicated to Agencies for Environment and Energy Management.

\section{References}

[1] M. A. Saidel, T. M. Reis, Jr F. A. A. Prado, "Carbon Credits and Energy Efficiency", International Journal of Green Energy 6 (3) (2009), pp. 312-322.

[2] G.D. Bolt, M. Kleingeld, J.F. van Rensburg, "Carbon tax: Future models and impact", Proceedings of the 8th Conference on the Industrial and Commercial Use of Energy, 2011, pp. $152-158$.

[3] J. Holmes, "A More Perfect Union: Energy Systems Integration Studies from Europe", IEEE Power and Energy Magazine 11 (5) (2013), pp. 36-45.
[4] D. Singh, N. K. Sharma, Y. R. Sood, R. K. Jarial, "Global status of renewable energy and market: Future prospectus and target", Proceedings of International Conference on Sustainable Energy and Intelligent Systems, 2011, pp.171-176.

[5] S. Favuzza, G. Graditi, M.G. Ippolito, F. Massaro, R. Musca, E.R. Sanseverino, G. Zizzo, "Transition of a distribution system towards an active network. Part I: Preliminary design and scenario perspectives", Proceedings of 2011 International Conference on Clean Electrical Power, 2011, pp. 9-14.

[6] I. Zubia, I. Arrambide, O. Azurza, P.M. García and J.J. Ugartemendia, "Rural Smart Grids: planning, operation and control review", Renewable Energy and Power Quality Journal 11 (2013).

[7] H.M. Hwang, J.B. Park, J.H. Rho, J.H. So, H.E. Song, G.J. Yu, "Comparative analysis of system economics for the Korean and German photovoltaic support program", Proceedings of IEEE Photovoltaic Specialists Conference, 2011, pp. 3254-3259.

[8] K. Ogimoto, I. Kaizuka, Y. Ueda, T. Oozeki, “A Good Fit: Japan's Solar Power Program and Prospects for the New Power System", IEEE Power and Energy Magazine 11 (2) (2013), pp. 65-74.

[9] A. Filipkowski, "Introducing future engineers to sustainable ecology problems: a case study", European Journal of Engineering Education 36 (6) (2011), pp. 537-546.

[10] H. Patel, V. Agarwal, "MATLAB-Based Modeling to Study the Effects of Partial Shading on PV Array Characteristics", IEEE Transactions on Energy Conversion 23 (1) (2008), pp. 302-310.

[11] O. Rompelman, E. De Graaff, "The engineering of engineering: curriculum development from a designer's point of view", European Journal of Engineering Education 31 (2) (2006), pp. 215-226.

[12] O. Goldstain, I. Ben-Gal, Y. Bukchin, "Remote learning for the manipulation and control of robotic cells", European Journal of Engineering Education 32 (4) (2007), pp. 481-494. 